\title{
Melhoria na eficiência energética de um armazém frigorificado através do método PDCA
}

DOI: https://doi.org/10.35168/2176-896X.UTP.Tuiuti.2020.Vol6.N61.pp88-121

Anselmo Eduardo Leme Brombal

Universidade Tuiuti do Paraná. aebrombal@gmail.com

Flaviano Cansi

Universidade Tuiuti do Paraná. flavianocansi@hotmail.com

Luiz Olivar Costa Bodot Universidade Tuiuti do Paraná. luizbodot7@gmail.com

Rodrigo Ramos Alves Universidade Tuiuti do Paraná. rodrigo.alves@utp.br

Miguelangelo Geimba de Lima

Universidade Tuiuti do Paraná. miguelangelo.lima@utp.br 


\section{Melhoria na eficiência energética de um armazém frigorificado através do método PDCA}

\section{Resumo}

As empresas modernas buscam o tempo todo formas eficazes de se destacar no mercado competitivo. Dessa forma, tornou-se cada vez mais importante conhecer e fazer uso das ferramentas administrativas existentes, na busca de inovação e consolidação de seus métodos para a melhoria da produtividade. O presente trabalho utilizou o método PDCA para implantar melhorias no processo de produção em de um armazém frigorífico localizado em Nova Santa Rita no Rio Grande do Sul. O tema escolhido foi relacionado a eficiência energética, um dos principais custos hoje de uma empresa deste segmento devido a necessidade em manter as câmaras deste armazém refrigeradas. Os resultados obtidos mostraram que o Ciclo PDCA pode trazer benefícios relevantes nos processos produtivos, e que, caso ocorra alguma adversidade em uma das etapas, pode-se recorrer ao uso de ferramentas complementares para garantir sua total eficácia. Concluiu-se que a gestão de todo o processo deve ser feita levando em consideração o que se tem de concreto, analisando cada etapa em suas estatísticas reais e não apenas teóricas.

Palavras-chave: PDCA. Melhoria. Consumo Energético. Refrigeração. 


\section{Improving the energy efficiency of a refrigerated warehouse through the PDCA method}

\section{Abstract}

Modern companies are constantly looking for effective ways to stand out in the competitive market. Thus, it became increasingly important to know and make use of the existing administrative tools, in the search for innovation and consolidation of its methods for improving productivity. The present work used the PDCA method to implement improvements in the production process in a cold store located in Nova Santa Rita in Rio Grande do Sul. The chosen theme was related to energy efficiency, one of the main costs today of a company in this segment due to the need to keep the chambers of this warehouse refrigerated. The results obtained showed that the PDCA cycle can bring relevant benefits in the production processes, and that, in case of any adversity in one of the stages, the use of complementary tools can be used to guarantee its total effectiveness. It was concluded that the management of the entire process must be done taking into account what is concrete, analyzing each step in its real statistics and not just theoretical ones.

Keywords: PDCA. Improvement. Energy Consumption. Refrigeration. 


\section{Melhoria na eficiência energética de um armazém frigorificado através do método PDCA}

\section{Introdução}

Em uma sociedade que experimenta cada vez mais transformações, ter conhecimento e informação é imprescindível. No caso das empresas, sobreviver em meio ao mercado competitivo só é possível através de recursos inovadores e contínuos, que permitam alcançar um bom gerenciamento de processos, visando à qualidade.

O método conhecido como PDCA é uma das ferramentas de gestão utilizadas na maioria das empresas, visando uma constante melhoria, nos processos produtivos. Porém, vista fora da teoria, nota-se que algumas das propostas estabelecidas são, praticamente, inalcançáveis, enquanto que outras são redundantes ao processo, facilmente atingíveis. A primeira situação gera frustração aos trabalhadores, e a segunda acarreta a estagnação.

Assim sendo, para assumir uma posição mais ousada no mercado, é importante que sejam aplicadas novas técnicas ou novos ajustes ao método gerencial de tomada de decisões, para que haja uma harmonia recíproca entre trabalhadores, setores administrativos e gerencias, e desses com o ambiente físico e cognitivo do trabalho.

O PDCA é um método de solução de problemas, que passa por 4 fases: "Planejar" (Plan P), "Atuação de um plano de Ação" (Do - D), "Verificação" (Check - C) e "Padronização e a Conclusão" (A - Action) (CAMPOS, 1992).

Fazendo uso do método PDCA, o objetivo deste trabalho foi desenvolver melhorias no processo de produção de um armazém frigorífico localizado em Nova Santa Rita no Rio Grande do Sul. O tema escolhido foi relacionado a eficiência energética, um dos principais custos hoje de uma empresa deste segmento devido a necessidade em manter as câmaras deste armazém refrigeradas. Somando-se a essa ferramenta uma constante auditoria em seus métodos, no intuito de avaliar na 


\section{Melhoria na eficiência energética de um armazém frigorificado através do método PDCA}

prática se sua aplicação é satisfatória. Foram utilizadas algumas ferramentas da qualidade tais como o Círculo de Controle de Qualidade, a Classificação ABC, o 5W2H, o Diagrama de Causa e Efeito, a técnica dos "5 porquês", o fluxograma e matriz de priorização nas etapas do PDCA.

De maneira geral, pretendeu-se aplicar um método que fosse guiado pela teoria cognitiva, incentivando, assim, o planejamento das ações. Neste sentido O método PDCA e estas ferramentas foram utilizadas através de sugestões dos colaboradores envolvidos nos processos.

\section{Material e métodos}

Nesta parte serão abordadas a fundamentação teórica, a descrição da empresa em estudo e o procedimento metodológico utilizado neste trabalho.

\subsection{Fundamentação teórica}

\subsubsection{Método PDCA}

A natureza repetida e cíclica da melhoria contínua é resumida pelo que é chamado de ciclo PDCA (ou ciclo de Deming). É a sequência de atividades que são percorridas de maneira cíclica para a melhoria dos processos, conforme indica a Figura 1. 


\section{Melhoria na eficiência energética de um armazém frigorificado através do método PDCA}

Figura 1 - Método PDCA

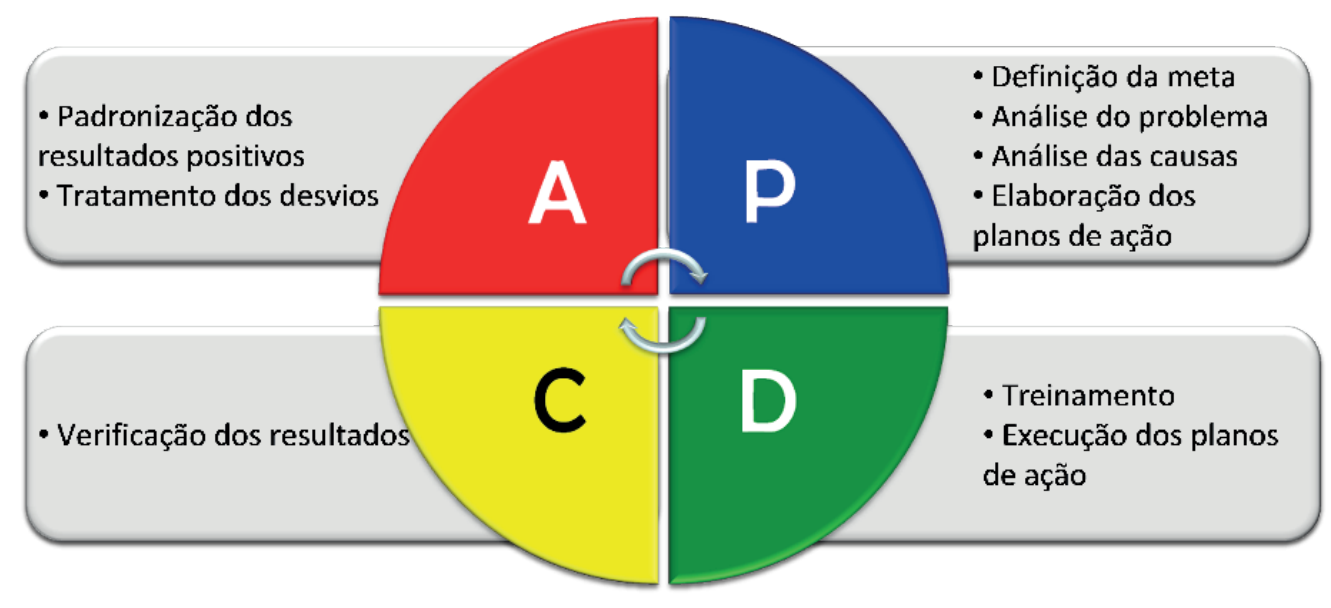

Fonte: Adaptado de Ishikawa (1986).

Este método é utilizado para encontrar soluções de problemas complexos e implementar melhorias. É dividido em 4 etapas, que são subdivididas em mais tarefas. É um ciclo de melhoria contínua e está demonstrado na figura 7: 


\section{Melhoria na eficiência energética de um armazém frigorificado através do método PDCA}

Figura 2 - Etapas do PDCA

\begin{tabular}{|c|c|c|c|}
\hline ETAPA & SEQUÊNCIA & ATIVIDADE & FERRAMENTA \\
\hline & & 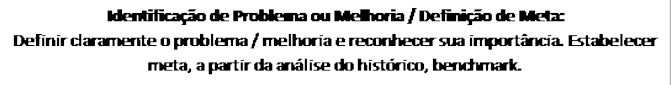 & \\
\hline & & 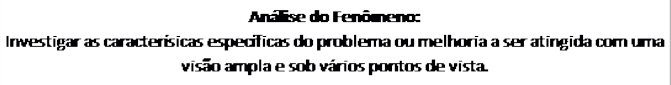 & \\
\hline & 3 & $\begin{array}{l}\text { Anát tse do Processoc } \\
\text { Descobrir as cansas fundamentais do problema ou que levem a atingir a melhoria }\end{array}$ & \\
\hline & & $\begin{array}{l}\text { Plano de Açāoc } \\
\text { Construir plano de açāo para bloquear as causas fundamentais. }\end{array}$ & \\
\hline & 5 & 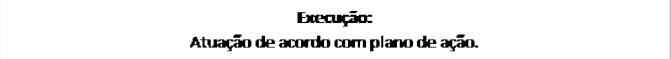 & \\
\hline & & $\begin{array}{l}\text { Verificapāos } \\
\text { Verificar se o bloqseio foi efetivo. }\end{array}$ & \\
\hline & & $\begin{array}{l}\text { Efetividade: } \\
\text { Bloqueio foi efetivo: Sim ou Não? }\end{array}$ & \\
\hline & 8 & $\begin{array}{l}\text { Padromizaçox } \\
\text { Prevenir contra o reaparecimento do problema ou garantia de que a melhoria se } \\
\text { manterá através do SDCA. }\end{array}$ & \\
\hline & 9 & $\begin{array}{l}\text { Conchusāox } \\
\text { Refletir solvre o método de soluçäo do problema e planejar trabalho futuro. }\end{array}$ & \\
\hline
\end{tabular}

Fonte: Adaptado de Ishikawa (1986). 


\section{Melhoria na eficiência energética de um armazém frigorificado através do método PDCA}

Para Ishikawa (1986), 95\% dos problemas de qualidade que as organizações enfrentam podem ser resolvidos com a utilização das ferramentas da qualidade, dentre as quais: a Matriz de Verificação, o Diagrama de Pareto, o Histograma, o Diagrama de causa e efeito o Fluxograma, entre outros.

\subsubsection{Ferramentas da qualidade}

a. Círculo de Controle de Qualidade (CCQ): é um conjunto de colaboradores que voluntariamente realizam reuniões regularmente em busca da qualidade em suas organizações (ISHIKAWA, 1986).

b. Fluxograma: Facilitando a visualização dos passos de um processo, o Fluxograma é uma representação gráfica que utiliza símbolos padronizados e que permite uma melhor análise para detecção de falhas e possíveis melhorias (PALADINI, 2008).

c. Diagrama de causa e efeito: Também conhecido como Diagrama de Ishikawa ou de espinha de Peixe é uma ferramenta de representação gráfica das possíveis causas que levam a um determinado defeito, utilizada na análise de problemas como na estruturação de decisões relativas a situações que devem ser eliminadas. A formação do Diagrama é elaborada através da análise de seis grandes fatores, também conhecidos por 6M. Deles são retiradas as causas para um determinado efeito. No entanto, devem ser tomados apenas como referência e não uma regra a ser seguida, já que em alguns processos não existirão, necessariamente, todos. São eles: matéria-prima, máquina, medida, meio ambiente, mão-de-obra e método (PALADINI, 2008).

d. Técnica dos "5 Porquês": A análise "porquê" é uma técnica simples, porém efetiva para ajudar a compreender as razões da ocorrência de problemas. É a técnica que estabelece 


\section{Melhoria na eficiência energética de um armazém frigorificado através do método PDCA}

a existência de determinado problema e como ele ocorreu, através da pergunta "porquê" (SLACK et al. 2002).

e. Matriz de Verificação: É uma ferramenta da qualidade que organiza e facilita a coleta de dados em um quadro ou tabela. Uma folha de verificação bem elaborada é o ponto de partida para que o problema possa ser subdividido em partes menores e assim sua a descrição possa ser bem focada e objetiva (BONIFÁCIO, 2006).

f. Classificação ABC: Também conhecido como gráfico ou diagrama de Pareto, tem como objetivo classificar os problemas que causam os maiores efeitos em ordem decrescente e resolve-los a priori. Desta forma, a solução é direcionada primeiramente aos problemas mais importantes (PALADINI, 2008). A base para a elaboração deste gráfico se sustenta no Princípio de Pareto, um economista sociopolítico do século XIX, que ao analisar a sociedade, concluiu que grande parte da riqueza se encontrava nas mãos de um número reduzido de pessoas, determinou matematicamente que $80 \%$ da riqueza estavam nas mãos de $20 \%$ da população. Posteriormente, J. M. Juran percebeu que a idéia de Pareto se aplicava aos problemas de qualidade (WERKEMA, 2012).

g. 5W2H: A ferramenta 5W2H é um checklist administrativo de atividades, prazos e responsabilidades que devem ser desenvolvidas com clareza e eficiência por todos os envolvidos em um projeto. Tem como função definir o que será feito, porque, onde, quem irá fazer, quando será feito, como e quanto custará. A sigla é formada pelas iniciais, em inglês, das sete diretrizes que, quando bem estabelecidas, eliminam quaisquer dúvidas que possam aparecer ao longo de um processo ou de uma atividade. Essa ferramenta consiste em responder 7 perguntas conforme abaixo na figura 3 . 


\section{Melhoria na eficiência energética de um armazém frigorificado através do método PDCA}

Figura 3 - Ferramenta 5W2H

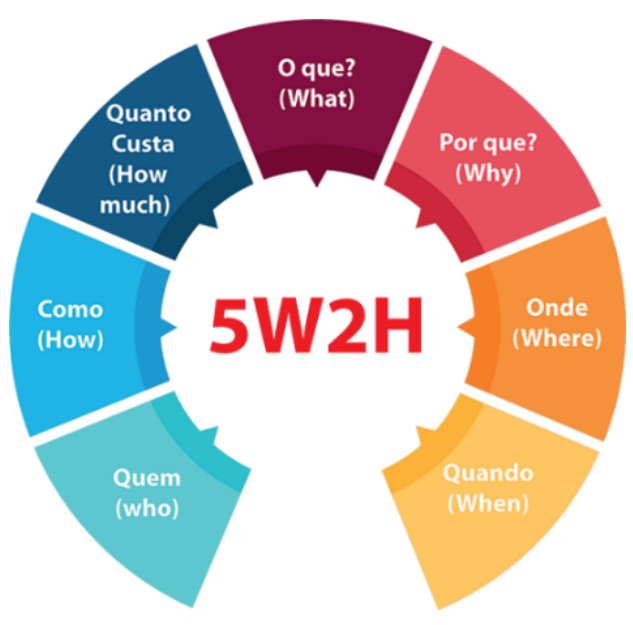

Fonte: adaptado de REYES (2000).

\subsection{A Empresa em estudo}

A energia elétrica é a principal fonte de energia do mundo. Faz parte do nosso cotidiano e necessária para realizarmos nossas atividades e tarefas. Os consumidores são divididos basicamente em dois grupos: residencial e industrial. Iremos abordar o uso industrial e o local escolhido foi um armazém frigorífico de uma empresa de alimentos de grande porte. Empresas utilizam energia elétrica em seus processos e o valor gasto é alto e representativo em seu custo operacional. A empresa faz parte de uma grande e complexa cadeia de suprimentos, especificamente fazendo o processo logístico e atendendo aos clientes (grandes redes de mercados e varejo) do estado do Rio Grande do Sul. Recebe, armazena e entrega produtos paletizados e refrigerados. 


\section{Melhoria na eficiência energética de um armazém frigorificado através do método PDCA}

Possui uma câmara de congelados com temperatura de quinze graus celsius negativos ou mais frio $\left(-15^{\circ} \mathrm{C}\right)$, uma câmara de resfriados com temperatura de zero até quatro graus positivos $\left(0^{\circ} \mathrm{C}\right.$ à $+4^{\circ} \mathrm{C}$ ) e uma antecâmara com temperatura entre quatro e dez graus positivos.

Possui rigorosos padrões de qualidade e para manter as temperaturas dentro dos padrões estipulados, utiliza-se um sistema de refrigeração por amônia anidra - fluido refrigerante altamente tóxico, mas com alto rendimento e inofensivo ao meio ambiente. Este sistema é hermético e é composto por alguns equipamentos e elementos de linha. São equipamentos que possuem motores com grandes potências e consequentemente são grandes consumidores de energia.

\subsection{Procedimento metodológico}

As pesquisas exploratórias têm o propósito de criar maior familiaridade com o problema para torná-lo mais explícito ou construir hipóteses. A coleta de dados geralmente envolve: levantamento bibliográfico; entrevistas e análise de informações. Estudo de caso e mesmo os levantamentos de campo são identificados como estudos exploratórios. (GIL, 2010).

Quanto à abordagem do problema as pesquisas são classificadas em Quantitativa e Qualitativa. A pesquisa qualitativa busca a subjetividade do sujeito que nem sempre pode ser traduzida em números, sendo descritiva, pois os pesquisadores tendem a analisar seus dados indutivamente. Quantificável significa traduzir em números opiniões e informações com o uso de recursos e técnicas estatísticas. É descritiva, pois os pesquisadores tendem a analisar seus dados indutivamente (OTAMI e FIALHO, 2011).

Neste sentido a pesquisa teve como objetivo realizar um levantamento e posteriormente a padronização do sistema de refrigeração por amônia da empresa em estudo. A abordagem foi 


\section{Melhoria na eficiência energética de um armazém frigorificado através do método PDCA}

qualitativa e quantitativa através de levantamento de dados do sistema da empresa. A pesquisa foi realizada em 2018.

Foram utilizados nesta pesquisa 6 etapas do Método PDCA com o apoio de ferramentas da qualidade. As etapas utilizadas foram: Identificação do problema, Análise do fenômeno, Análise do processo, Plano de Ação e Execução, Verificação e Padronização.

\section{Resultados e discussão}

O armazém escolhido fica localizado em Nova Santa Rita no Rio Grande do Sul. Em resumo, toda operação e manutenção do local era feita por equipe terceirizada e era feita de maneira adequadas. Instalações precárias e construções fora de norma. Ocorreram alguns acontecimentos em um armazém situado ao lado e como forma de prevenir algo parecido a empresa decidiu executar estas atividades de operação e manutenção com equipe técnica própria. Em julho de dois mil e dezoito foram contratadas nove pessoas para compor esta equipe de manutenção, que junto com outras pessoas da área e as três pessoas que formam o grupo de melhoria que desenvolveram o trabalho.

A empresa possui um programa de Círculos de Controle Qualidade (CCQ) que visam identificar problemas no processo e promover melhorias através do PDCA e das ferramentas de qualidade. A equipe foi composta por três facilitadores e doze funcionários (gerente de logística, engenheiro eletricista, técnicos eletricistas, técnico de refrigeração, mecânicos, operadores de refrigeração e estagiário).

Após definição dos membros da equipe, foi definida uma meta e as etapas do projetos suscintamente descritas no contrato de melhoria. 


\section{Melhoria na eficiência energética de um armazém frigorificado através do método PDCA}

\subsection{Elaboração do contrato de melhoria}

O contrato de melhoria foi elaborado com a participação de todos os integrantes da equipe. Neste contrato foi informado alguns dados básicos como descrição geral do projeto, razões para realizar o projeto, business case, problema, restrições para execução do projeto, atividades iniciais e cronograma.

\subsection{Descrição do projeto}

O trabalho será executado no armazém frigorífico localizado em Nova Santa Rita - RS, unidade de armazenagem e expedição da empresa.

A manutenção do local era feita por empresa terceira, e era precária. Devido a isto, em julho de dois mil e dezoito foram contratadas 9 pessoas para equipe própria de operação e manutenção.

Foi apresentado a ferramenta PDCA à equipe, como forma de desenvolvimento pessoal e profissional e o tema escolhido foi consumo de energia, devido ao impacto que uma melhoria relacionada a este tema pode causar nos resultados financeiros da empresa. Estabelecemos como meta a melhoria de um indicador de eficiência energética, obtido através de uma relação de consumo de energia dado em quilowatt-hora ( $\mathrm{kwh}$ ) e volume movimentado no armazém dado em tonelada. O resultado desta relação é um indicador de kwh gasto por tonelada movimentada neste armazém no mês. A redução proposta foi de $7 \%$ em relação ao mesmo período do ano de dois mil e dezessete e para comparar os resultados de forma efetiva utiliza-se os mesmos meses devido a sazonalidade do produto neste período do ano (alimentos consumidos na época de Natal, nos meses de setembro, outubro e novembro). O volume movimentado aumenta cerca de vinte por cento em relação aos demais meses do ano e o consumo de energia também. 


\section{Melhoria na eficiência energética de um armazém frigorificado através do método PDCA}

Para medição dos dados e dos resultados de cada etapa, os meses foram divididos em semanas, devido ao período estabelecido para este trabalho.

\subsection{Business Case}

Para melhoria na eficiência energética no armazém frigorífico de Nova Santa Rita - RS, trabalhamos na redução consumo e consequentemente no custo de energia, contribuindo para os resultados financeiros da empresa.

- Média de consumo mensal (ano) em 2017: $235.000 \mathrm{kwh} / \mathrm{mês}$

- Média de custo mensal (ano) em 2017: R\$56.666/mês

- Média de custo mensal (ano) do kwh em 2017: R\$0,24

- Média de volume mensal (ano) em 2017: 12.219 toneladas/mês

- Média do Indicador de kwh/ton (ano) em 2017: 19,2/mês

Os dados acima estão descritos no quadro 1:

Quadro 1- Dados de 2017 para comparação

\begin{tabular}{|c|c|c|c|c|c|c|c|c|c|c|c|c|c|}
\hline & jan/17 & $\mathrm{v} / \mathbf{1 7}$ & $\operatorname{mar} / 17$ & abr/17 & mai/17 & jun/17 & jul/17 & ago/17 & set/17 & out $/ 17$ & nov/17 & $\mathrm{dez} / \mathbf{1} 7$ & TOTAL \\
\hline & & & & & & & & & & & & & \\
\hline KWn & 1.753 & 8.433 & | & 202.011 & 256.545 & 199.494 & 195.561 & 206.202 & 218.343 & & & & \\
\hline & 18,96 & 22,31 & 24,65 & 27,95 & 20,67 & 16,11 & 15,55 & 16,08 & 18,49 & 16,75 & 16,67 & 18,80 & 19,20 \\
\hline $\begin{array}{l}\text { Custo me } \\
\text { Energia }\end{array}$ & $\begin{array}{c}\mathrm{R} \$ \\
85.842\end{array}$ & \begin{tabular}{|c|}
$\mathrm{R} \$$ \\
113.885 \\
\end{tabular} & $\begin{array}{c}\mathrm{R} \$ \\
103.551\end{array}$ & $\begin{array}{c}\mathrm{R} \$ \\
46.542\end{array}$ & $\begin{array}{c}\mathrm{R} \$ \\
59.934\end{array}$ & $\begin{array}{c}\mathrm{R} \$ \\
37.469\end{array}$ & & $\begin{array}{c}\mathrm{R} \$ \\
41.992\end{array}$ & $\begin{array}{c}\mathrm{R} \$ \\
36.294\end{array}$ & $\begin{array}{c}\mathrm{R} \$ \\
41.694\end{array}$ & $\begin{array}{c}\mathrm{R} \$ \\
37.856\end{array}$ & $\begin{array}{c}\mathrm{R} \$ \\
37.498\end{array}$ & $\begin{array}{c}\mathrm{R} \$ \\
679.997\end{array}$ \\
\hline Custo kwh & $\$ 0,43$ & S0,48 & $R S 0,33$ & $R S 0,16$ & $R S 0,23$ & $R S 0,19$ & $R S 0,19$ & $R S 0,20$ & RS 0,17 & RS 0,18 & RS 0,16 & $R S 0,15$ & $R S 0,24$ \\
\hline
\end{tabular}

Fonte: autores (2018). 


\section{Melhoria na eficiência energética de um armazém frigorificado através do método PDCA}

Os dados de dois mil e dezessete irão servir de base de estudo para estabelecimento das metas e verificação da eficácia do projeto. Através da análise destes dados e do conhecimento do processo, identificamos que temos um maior volume entre os meses de setembro e dezembro, devido a sazonalidade do produto comercializado pela empresa nestes meses do ano.

\subsection{Definição do problema e metas}

O problema definido foi o alto consumo de energia elétrica no armazém frigorífico da empresa. Após analisar os dados e ganhos do projeto em discussão em sala de aula com professor e integrantes do grupo, notou-se que devido a sazonalidade não iriamos conseguir mensurar esta melhoria somente com o consumo. Historicamente, de setembro a dezembro, a empresa aumenta a movimentação do armazém devido a época do Natal. Este aumento do volume chega a vinte por cento da média dos demais meses do ano e isto impacta diretamente no consumo de energia do local devido a dinâmica do sistema de refrigeração que iremos explicar.

Em resumo, um armazém frigorífico funciona como uma grande geladeira e ao abrir e fechar suas portas, há infiltração de ar quente e umidade, fazendo com que o sistema tenha que trabalhar mais para suprir a necessidade do frio e conhecendo os fundamentos da termodinâmica o trabalho é maior, e consequentemente o consumo/custo com energia elétrica também.

Então foi definido que o indicador que iremos utilizar para mensurar o ganho do projeto é um indicador de eficiência e não consumo. Esta eficiência é obtida através da relação entre o consumo em quilowatt-hora dividido pela movimentação em toneladas. Assim, conseguiremos acompanhar e verificar a eficácia de cada ação tomada durante o período do projeto.

Para definição da meta, propomos reduzir 7\% do indicador (kwh/ton) em relação ao mesmo período de dois mil e dezessete, com base nos meses de setembro, outubro e novembro, período do projeto. 


\section{Melhoria na eficiência energética de um armazém frigorificado através do método PDCA}

Devido ao tempo dado para execução deste projeto de melhoria, definimos que as medições dos resultados de cada ação seriam semanais, e as ferramentas e softwares utilizados são de propriedade da empresa.

Para medição do consumo de energia, foi utilizada a plataforma Webenergy, um sistema de medição on-line do consumo de energia elétrica do armazém. Este sistema permite ao usuário leituras de consumo, demanda, fator de potência e outros dados que contribuíram para a execução deste projeto, conforme figura 4:

\section{Figura 4 - Sistema de Medição de Energia:WEBENERGY}

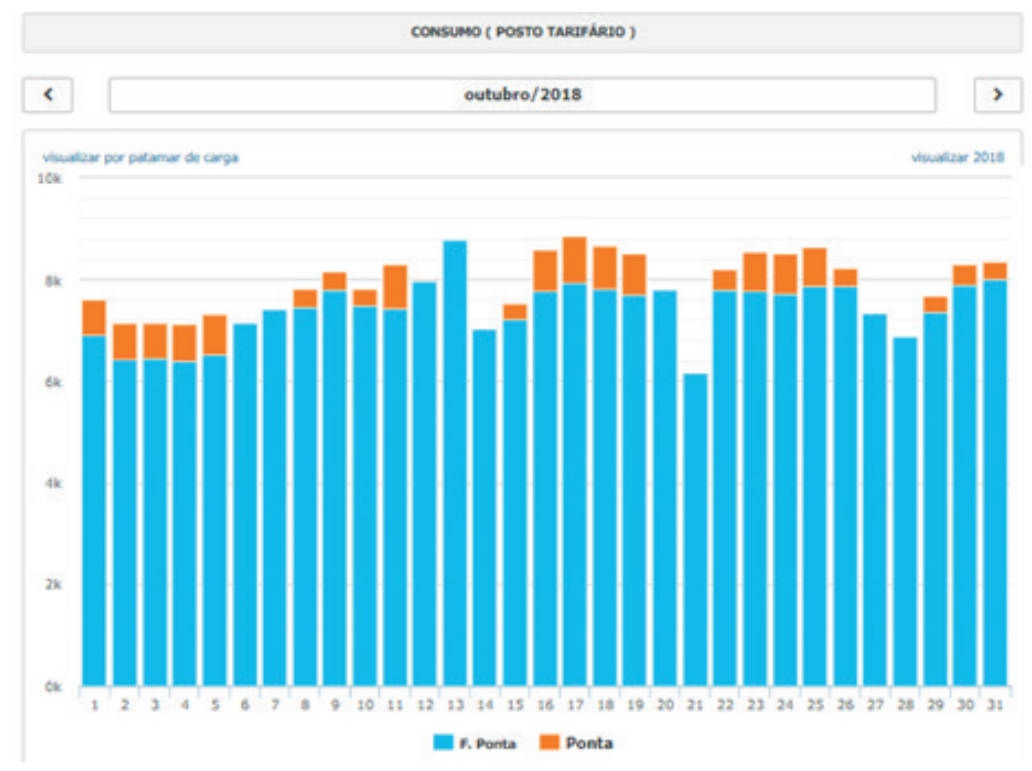

Fonte: WEBENERGY (2018). 


\section{Melhoria na eficiência energética de um armazém frigorificado através do método PDCA}

Para medição do volume movimentado do armazém foram utilizados dados do sistema ERP (Enterprise Resource Planning, ou Planejamento dos Recursos da Empresa) utilizado na empresa, o SAP.

\subsection{Restrições}

Para execução do projeto foram identificadas algumas dificuldades como:

- Tempo hábil para elaboração do PDCA;

- Tempo para implementação das ações;

- Limitação no valor do investimento;

\subsection{Cronograma}

Para obter resultados eficientes devemos planejar cada etapa do projeto. Para fazer o planejamento foi estabelecido um cronograma utilizando um software de edição de projetos: o Microsoft Project. Nele foram estabelecidas as ações, assim como as datas previstas para execução. O intuito em se elaborar o cronograma é ter a visibilidade de todo o projeto, suas sub tarefas e a evolução de cada etapa.

O cronograma foi definido em reunião com os envolvidos, as datas foram acordadas e consensadas com toda equipe participante e sofreram alterações durante a execução devido a estarmos estudando e conhecendo o método PDCA e o sistema de refrigeração e suas variáveis.

A figura 5 demonstra uma visão macro do projeto, e seus detalhes estão detalhados em arquivo eletrônico do Microsoft Project. 


\section{Melhoria na eficiência energética de um armazém frigorificado através do método PDCA}

Figura 5 - Visão geral do Projeto

\begin{tabular}{|c|c|c|c|c|c|}
\hline (i) & Nome da Tarefa & Duração * & Início & Término & Texto1 \\
\hline & $\begin{array}{l}\triangle \text { PROJETO DE MELHORIA-EFICIÊNCIA } \\
\text { ENERGÉTICA }\end{array}$ & 86 dias & Qua 15/08/18 & Qua 12/12/18 & \\
\hline$\checkmark$ & Reunião Kick-off & 1 dia & Qua 15/08/18 & Qua 15/08/18 & Apresentação do projeto e definição dos responsáveis; \\
\hline$\checkmark$ & $\triangle \mathrm{P}$ - PLAN (Planejar) & 20 dias & Sex $17 / 08 / 18$ & Sex 14/09/18 & \\
\hline$\checkmark$ & $\begin{array}{l}\text { P - Identificação do problema/Definição de } \\
\text { metas; }\end{array}$ & 2 diasd & Sex 17/08/18 & Dom 19/08/18 & Definição do problema, meta e coleta de dados; \\
\hline$\checkmark$ & P - Coleta de Dados & 6 diasd & Seg 20/08/18 & Dom 26/08/18 & Coleta de dados do processo (fluxograma, diagramas); \\
\hline$\checkmark$ & P - Elaboração de Fluxograma & 2 dias & Seg 27/08/18 & Ter 28/08/18 & \\
\hline$\checkmark$ & P - Análise do fenômeno/Processo; & 1 dia & Qua 29/08/18 & Qui 30/08/18 & Elaboração do Diagrama de Pareto/Extratificação; \\
\hline$\checkmark$ & P - Brainstorming & 1 dia & Sex 31/08/18 & Sex 31/08/18 & Registrado em Ata com todos os integrantes da equipe; \\
\hline$\checkmark$ & P - Diagrama de Ishikawa & 1 dia & Seg 03/09/18 & Seg 03/09/18 & Utilizando o Método de espinha de peixe e a metodologia $6 \mathrm{M}$ 's; \\
\hline$\checkmark$ & P - Análise das hipóteses & 1 dia & Ter 04/09/18 & Ter 04/09/18 & Nesta etapa são julgadas as possiveis causas e seus respectivos motivos; \\
\hline$\checkmark$ & $P$ - Teste dos Porquês & 1 dia & Qua 05/09/18 & Qua 05/09/18 & Verificação das causas possiveis através da metodologia dos testes dos porquês; \\
\hline$\checkmark$ & P - Priorização das Causas & 1 dia & Qui 06/09/18 & Qui 06/09/18 & Priorizar as causas de acordo com sua relevância: Impacto, Autonomia, Custo e Prazo; \\
\hline$\checkmark$ & P - Elaboração Plano de Ação & 4 diasd & Seg 10/09/18 & Sex 14/09/18 & Utilizando a metodologia $5 \mathrm{~W} 2 \mathrm{H}$; \\
\hline \multirow[t]{3}{*}{$\checkmark$} & Entrega do contrato do projeto de melhoria; & 1 dia & Sex 05/10/18 & Sex 05/10/18 & Apresentação em sala de aula, correções sugeridas e inserção de novo membro na equif \\
\hline & $D$ D - DO (Executar) & 52 dias & Qui 20/09/18 & Sex 30/11/18 & \\
\hline & $D$ C - CHECK (Verificar) & 42 dias & Qui 20/09/18 & Sex 16/11/18 & \\
\hline$\checkmark$ & Entrega do Artigo (prévia); & 1 dia & Sex 09/11/18 & Sex 09/11/18 & Entrega de Artigo com Evoluções do Trabalho de Melhoria Energética; \\
\hline \multirow[t]{2}{*}{$\checkmark$} & Reunião para elaboração versão final do artigo; & 2 dias & Qui 15/11/18 & Sex 16/11/18 & Elaborado versão final do artigo para entrega; \\
\hline & A - ACT (Padronizar) & 60 dias & Qui 20/09/18 & Qua 12/12/18 & \\
\hline
\end{tabular}

Fonte: autores (2018).

\subsection{Método PDCA}

Conforme informado no início do projeto, foi utilizada o método PDCA. Suas etapas serão descritas a seguir.

\subsubsection{Identificação do problema}

O problema escolhido pelo grupo e acordado via contrato de projeto de melhoria foi: alto consumo de energia no armazém. 


\section{Melhoria na eficiência energética de um armazém frigorificado através do método PDCA}

Este problema foi escolhido devido sua complexidade e aos resultados de eficiência e financeiro esperados com a execução e sucesso do projeto.

\section{a) Fluxograma}

Para entendermos melhor o problema, precisamos identificar quem são os maiores ofensores do consumo de energia.

O consumo de energia é obtido através do consumo em kwh. Para calcular o consumo utilizamos a potência dos equipamentos instalados dada em watt $(\mathrm{W})$, multiplicando pelo tempo em que permanecem ligados., por último é multiplicado pela eficiência de cada motor.

A potência (P) dada em watt (W) é obtida multiplicando a corrente elétrica (I) dada em ampér (A) e tensão dada em volt $(\mathrm{V})$, conforme fórmula abaixo:

$$
P=V \times I
$$

Sendo assim, sabemos que quanto maior a corrente do motor elétrico, maior será a potência e consequentemente o consumo de energia.

Foi disponibilizado o diagrama unifilar do armazém, assim como o fluxograma do sistema de refrigeração e foram coletados os seguintes dados:

- Quantidade de equipamentos;

- Quantidade de motores;

- Potência dos motores; 


\section{Melhoria na eficiência energética de um armazém frigorificado através do método PDCA}

- Rendimento;

- Horas trabalhadas (mês);

- $\quad$ Dias de trabalho;

\subsubsection{Análise do fenômeno}

Através de cálculos executados pela equipe, foi realizado o gráfico de pareto para análise, afim de identificar os principais consumidores de energia do armazém, conforme quadro 2 e figura 6 :

Quadro 2 - Primeira estratificação: Armazém

\begin{tabular}{|l|c|c|c|}
\hline \multicolumn{4}{|c|}{$1^{\circ}$ ESTRATIFICAÇÃO - CONSUMO MENSAL } \\
\hline Descrição item & Valor (kwh) & $\mathbf{( \% )}$ & (\%) total \\
\hline Sistema de Refrigeração & 218 & $77 \%$ & $77 \%$ \\
\hline Tomadas Frigoríficas & 23 & $8 \%$ & $85 \%$ \\
\hline Iluminação & 21 & $7 \%$ & $92 \%$ \\
\hline Sala de bateiras & 12 & $4 \%$ & $96 \%$ \\
\hline Outros & 10 & $4 \%$ & $100 \%$ \\
\hline
\end{tabular}

Fonte: autores (2018). 


\section{Melhoria na eficiência energética de um armazém frigorificado através do método PDCA}

Figura 6 - Gráfico de Pareto: Armazém

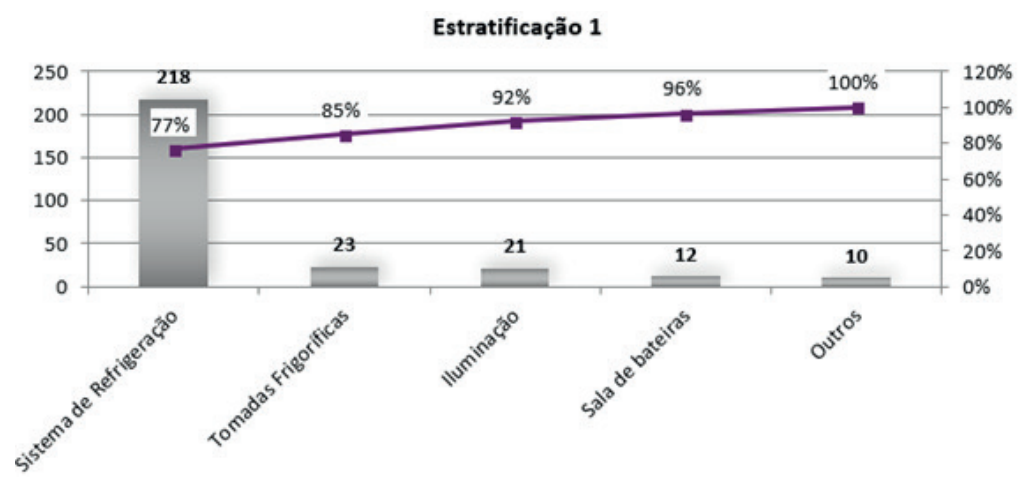

Fonte: autores (2018).

Observando o gráfico de pareto, podemos afirmar que 77\% do consumo de energia do armazém está atrelado ao sistema de refrigeração do armazém.

Através da análise destes dados redefinimos o problema: alto consumo de energia no sistema de refrigeração.

\subsubsection{Análise do processo do sistema de refrigeração por amônia}

A refrigeração funciona como meio de eliminar calor de um conjunto ou espaço, restringindo gradativamente à temperatura por trabalhos mecânicos ou naturais. Este resfriamento se dá por meio de ciclos termodinâmicos, os quais utilizam um método para o alcance de refrigeração de modo ininterrupto, em que o fluido, dito de refrigerante, percorre uma sequência de processos, retornando à sua condição original (STOECKER e JABARDO, 2002). 


\section{Melhoria na eficiência energética de um armazém frigorificado através do método PDCA}

Um sistema de refrigeração por amônia é composto por alguns componentes como fluido refrigerante (neste caso a amônia) compressores, reservatórios de líquido, bombas, evaporadores, condensadores, tubulações e elementos de linha como válvulas e manômetros. conforme figura 7:

Figura 7 - Trecho do fluxograma do sistema de refrigeração

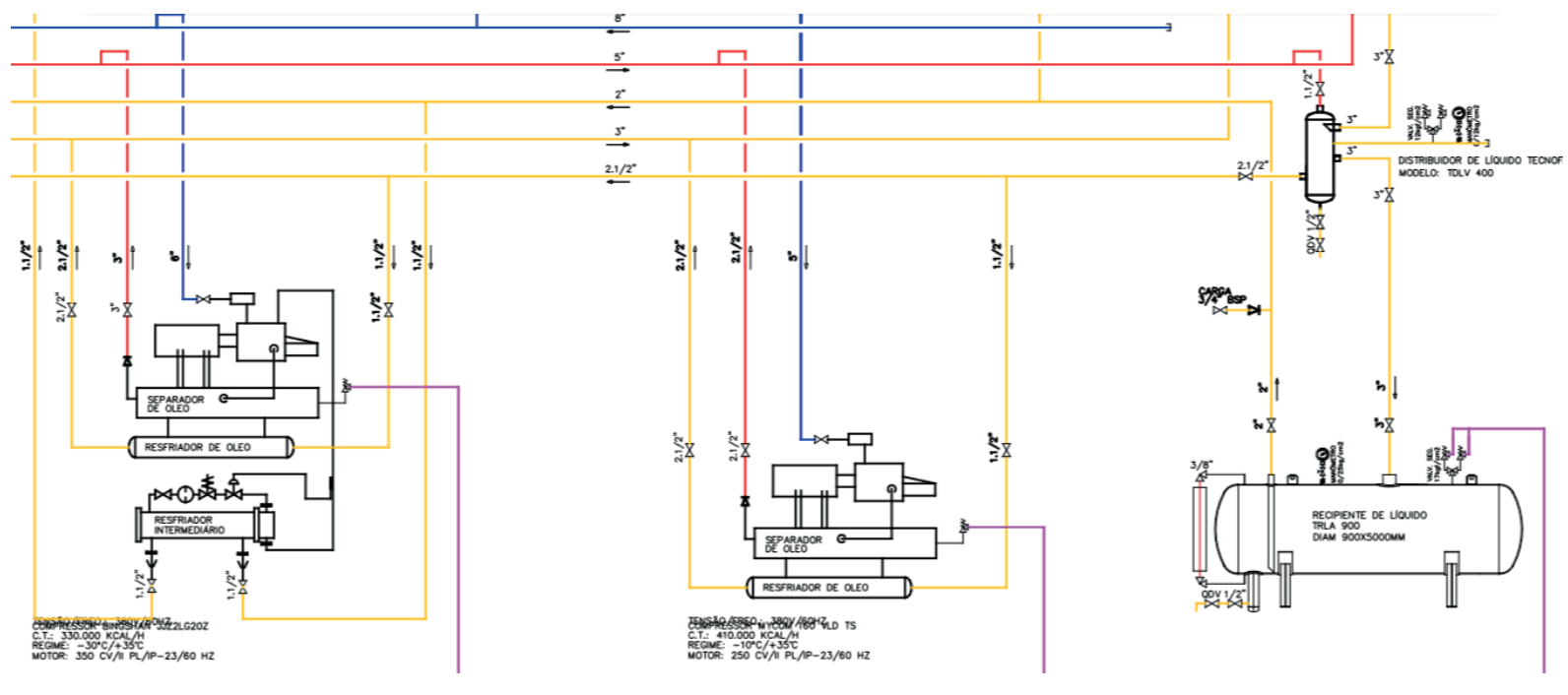

Fonte: autores (2018).

Após entender a dinâmica de funcionamento do sistema, suas variáveis e observar o impacto que este sistema causa no consumo de energia, foram estratificados os dados específicos, conforme quadro 3 e figura 8: 


\section{Melhoria na eficiência energética de um armazém frigorificado através do método PDCA}

Quadro 3 - Segunda estratificação: Sistema de Refrigeração

\begin{tabular}{|l|c|c|c|}
\hline \multicolumn{4}{|c|}{$\mathbf{2}^{\mathbf{a}}$ ESTRATIFICAÇ̃̃O - CONSUMO MENSAL } \\
\hline Abertura & Valor (kwh) & $\mathbf{( \% )}$ & $\mathbf{( \% )}$ total \\
\hline Compressor Bingshan & 105756 & $48 \%$ & $48 \%$ \\
\hline Compressor Mycom & 75383 & $35 \%$ & $83 \%$ \\
\hline Evaporadorores Congelados & 13243 & $6 \%$ & $89 \%$ \\
\hline Evaporadores Resfriados & 9081 & $4 \%$ & $93 \%$ \\
\hline Ventilador Condensador & 5299 & $2 \%$ & $96 \%$ \\
\hline Bombas de Amônia & 4629 & $2 \%$ & $98 \%$ \\
\hline Motobomba Condensador & 2481 & $1 \%$ & $99 \%$ \\
\hline Evaporadores Antecâmara & 2271 & $1 \%$ & $100 \%$ \\
\hline
\end{tabular}

Fonte: autores (2018).

Figura 8 - Gráfico de Pareto: Sistema de Refrigeração

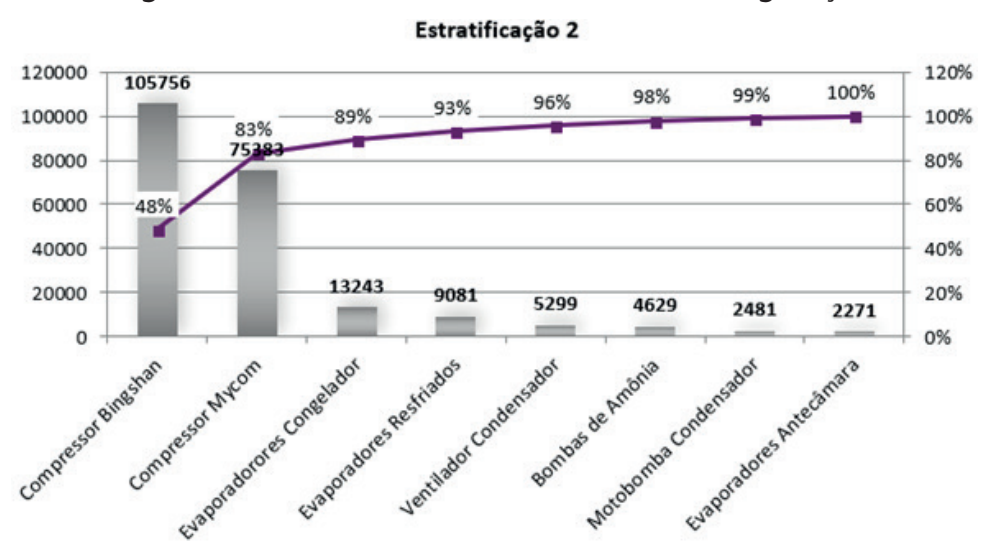

Fonte: autores (2018). 


\section{Melhoria na eficiência energética de um armazém frigorificado através do método PDCA}

A partir da análise profunda dos dados obtidos do sistema de refrigeração, realizamos o brainstorming ou tempestade de idéias. Todas as pessoas foram ouvidas e todas as idéias foram colocadas, para posteriormente serem julgadas. Elaboramos o diagrama de Ishikawa, utilizando o método dos 6 M's:

- Meio Ambiente;

- Máquina;

- Medida;

- Material;

- Método;

- Mão de Obra.

a) Diagrama de Ishikawa: Com o diagrama de Ishikawa pudemos levantar as causas possíveis para posteriormente definir as causas fundamentais, demonstrado na figura 9: 


\section{Melhoria na eficiência energética de um armazém frigorificado através do método PDCA}

Figura 9 - Diagrama de Ishikawa
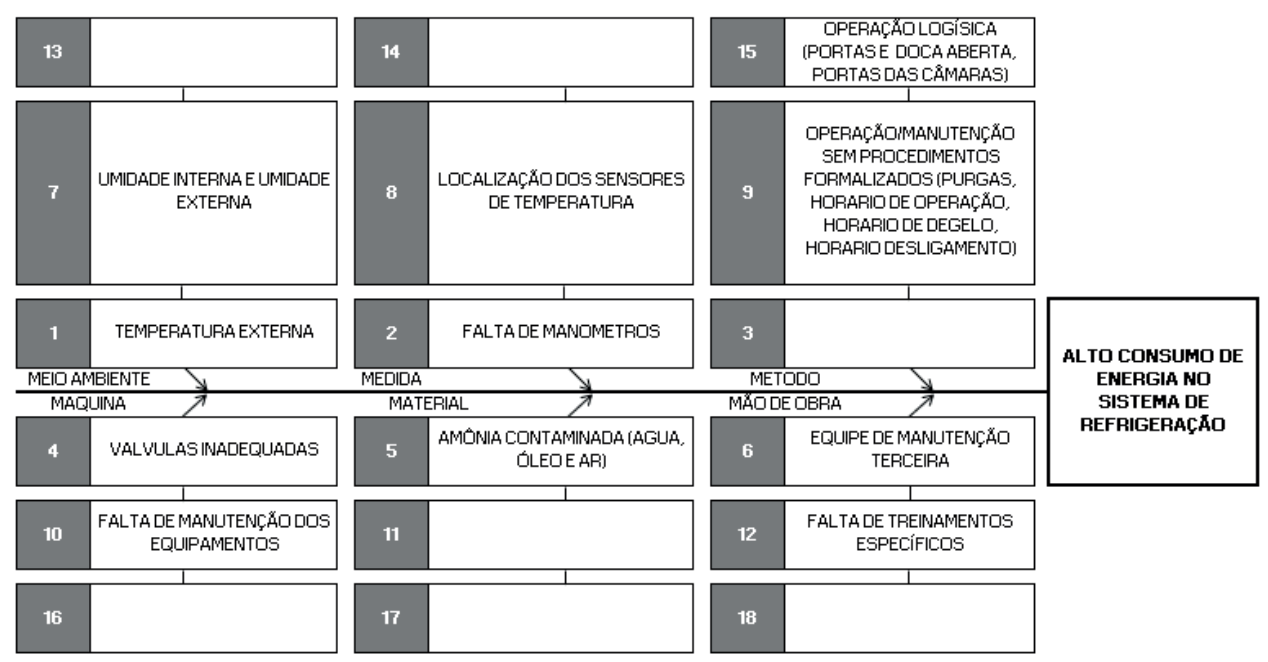

Fonte: autores (2018).

b) Julgamento de hipóteses: Após levantarmos as possíveis causas, elas foram julgadas e classificadas como prováveis ou pouco prováveis. Devido as discussões serem feitas com equipe técnica, a maioria das causas levantadas eram prováveis conforme descrito a seguir:

- Temperatura e umidade interna e externa: Provável, pois a entrada de ar quente e úmido devido a movimentação de produtos faz com que o sistema tenha que exercer um trabalho maior para atingir a temperatura padrão;

- Operação logística do armazém: Provável, pois ao abrir e fechar as docas (recebimento e expedição de veículos) o ar quente e úmido entra no armazém. 


\section{Melhoria na eficiência energética de um armazém frigorificado através do método PDCA}

- Falta de manômetros / instrumentação: Provável, pois a falta de leitura dos parâmetros do sistema impossibilita uma avaliação precisa de dados para tomadas de decisão, além de não oferecer confiabilidade;

- Operação e Manutenção sem procedimentos formalizados (purgas, horários de funcionamento do sistema de refrigeração, horários de degelo e planos de manutenção);

- Contaminação do fluído refrigerante: Provável, pois devido ao histórico levantado com antigos operadores nunca haviam sido eliminadas ou purgadas as contaminações do sistema como óleo, água (umidade) e ar. A contaminação do fluido refrigerante tem impacto direto no rendimento do sistema;

- Válvulas inadequadas: Provável, pois foi detectado que as válvulas eram de baixa qualidade e haviam sido reutilizadas de antigas instalações frigoríficas. Muitas das válvulas davam passagem e não funcionavam corretamente;

- Falta de manutenção nos equipamentos do sistema de refrigeração: Provável, pois eram feitas somente as manutenções corretivas;

- Equipe de manutenção terceirizada: Devido a equipe ser terceirizada, a empresa não tinha autonomia para definir os métodos e manutenções.

Notamos que muitas hipóteses poderiam tendenciar para uma mesma causa, então foram agrupados algumas para realizar o teste dos porquês.

c) Testes dos Porquês: $O$ teste dos porquês é feito afim de encontrar as causas fundamentais e posteriormente ser elaborado plano de ação efetivo. As causas estão descritas no quadro 4. 


\section{Melhoria na eficiência energética de um armazém frigorificado através do método PDCA}

Quadro 4 - Teste dos Porquês

\begin{tabular}{|c|c|c|}
\hline Porquê? & Motivo & Causa Fundamental \\
\hline $\begin{array}{l}\text { Temperatura e umidade interna / } \\
\text { externa }\end{array}$ & $\begin{array}{l}\text { Entrada de ar úmido devido a } \\
\text { operação logística. }\end{array}$ & \multirow{4}{*}{$\begin{array}{l}\text { Falta de instrução formal e } \\
\text { controle para os operadores } \\
\text { quanto a utilização das portas e } \\
\text { docas. }\end{array}$} \\
\hline $\begin{array}{l}\text { Entrada de ar úmido devido a } \\
\text { operação logística. }\end{array}$ & $\begin{array}{l}\text { Permanência de portas e docas } \\
\text { abertas, muitas vezes sem } \\
\text { necessidade. }\end{array}$ & \\
\hline $\begin{array}{l}\text { Permanência de portas e docas } \\
\text { abertas, muitas vezes sem } \\
\text { necessidade. }\end{array}$ & $\begin{array}{l}\text { Operadores deixam as portas e docas } \\
\text { abertas durante a movimentação / } \\
\text { manobra dos veículos. }\end{array}$ & \\
\hline $\begin{array}{l}\text { Operadores deixam as portas e } \\
\text { docas abertas durante a } \\
\text { movimentação / manobra dos } \\
\text { veículos. }\end{array}$ & $\begin{array}{l}\text { Falta de instrução formal e controle } \\
\text { para os operadores abrirem as portas } \\
\text { somente quando o veículo estiver } \\
\text { encostado. }\end{array}$ & \\
\hline \multicolumn{3}{|l|}{ Causa 2: Falta de manômetros } \\
\hline Falta de manômetros & $\begin{array}{l}\text { Falta de leitura dos parâmetros do } \\
\text { sistema (pressões de trabalho, } \\
\text { temperaturas) impossibilita uma } \\
\text { avaliação precisa dos dados. }\end{array}$ & \multirow[t]{2}{*}{$\begin{array}{l}\text { Falta de leitura dos parâmetros do } \\
\text { sistema (pressões de trabalho, } \\
\text { temperaturas) impossibilita uma } \\
\text { avaliação precisa dos dados. }\end{array}$} \\
\hline $\begin{array}{l}\text { Falta de leitura dos parâmetros do } \\
\text { sistema (pressões de trabalho, } \\
\text { temperaturas) impossibilita uma } \\
\text { avaliação precisa dos dados. }\end{array}$ & & \\
\hline \multicolumn{3}{|c|}{ Causa 3: Falta de manutenção dos equipamentos } \\
\hline $\begin{array}{l}\text { Falta de manutenção dos } \\
\text { equipamentos }\end{array}$ & $\begin{array}{l}\text { Responsabilidade de operação e } \\
\text { manutenção do sistema de } \\
\text { refrigeração é de equipe terceira e } \\
\text { não seguem os requisitos mínimos } \\
\text { estipulados pelo fabricante. }\end{array}$ & \multirow[t]{3}{*}{$\begin{array}{l}\text { Falta de autonomia na estratégia } \\
\text { de manutenção do sistema de } \\
\text { refrigeração. }\end{array}$} \\
\hline $\begin{array}{l}\text { Responsabilidade de operação e } \\
\text { manutenção do sistema de } \\
\text { refrigeração é de equipe terceira e } \\
\text { não seguem os requisitos mínimos } \\
\text { estipulados pelo fabricante. }\end{array}$ & $\begin{array}{l}\text { Falta de autonomia na estratégia de } \\
\text { manutenção do sistema de } \\
\text { refrigeração. }\end{array}$ & \\
\hline $\begin{array}{l}\text { Falta de autonomia na estratégia } \\
\text { de manutenção do sistema de } \\
\text { refrigeração. }\end{array}$ & & \\
\hline \multicolumn{3}{|c|}{ Causa 4: Operação e manutenção sem procedimento formalizado } \\
\hline $\begin{array}{l}\text { Operação e manutenção sem } \\
\text { procedimento formalizado }\end{array}$ & & $\begin{array}{l}\text { Operação e manutenção sem } \\
\text { procedimento formalizado } \\
\text { (purgas, horários de ligar e } \\
\text { desligar, planos de manutenção). }\end{array}$ \\
\hline \multicolumn{3}{|l|}{ Causa 5: Amônia contaminada } \\
\hline Amônia contaminada & $\begin{array}{l}\text { Presença de contaminantes como } \\
\text { água, óleo e ar no sistema. }\end{array}$ & \multirow{2}{*}{$\begin{array}{l}\text { Amônia era reutilizada de outras } \\
\text { instalações frigoríficas e não eram } \\
\text { feitos os procedimentos de análise } \\
\text { e descontaminação. }\end{array}$} \\
\hline $\begin{array}{l}\text { Presença de contaminantes como } \\
\text { água, óleo e ar no sistema. }\end{array}$ & $\begin{array}{l}\text { Amônia era reutilizada de outras } \\
\text { instalações frigoríficas e não eram } \\
\text { feitos os procedimentos de análise e } \\
\text { descontaminação. }\end{array}$ & \\
\hline
\end{tabular}

Fonte: autores (2018). 


\section{Melhoria na eficiência energética de um armazém frigorificado através do método PDCA}

d) Priorização de causas: Após o teste dos porquês, foi feita a priorização das causas levando em consideração alguns itens como impacto no processo, autonomia, custo e prazo. Foram atribuídas notas de um a cinco; sendo 5 um alto impacto e 1 baixo impacto. Os valores então foram multiplicados a uma classificação decrescente para o plano de ação, conforme quadro 5:

Quadro 5 - Julgamento das causas fundamentais

\begin{tabular}{|l|l|c|c|c|c|c|}
\hline \multicolumn{2}{|c|}{ Causa fundamental } & Impacto & Autonomia & Custo & Prazo & Total \\
\hline 1 & $\begin{array}{l}\text { Falta de instrução formal para os operadores } \\
\text { somente abrirem as portas no momento que o } \\
\text { veículo estiver estacionado }\end{array}$ & 3 & 3 & 1 & 1 & 9 \\
\hline 2 & $\begin{array}{l}\text { Falta de leitura dos parâmetros impossibilita uma } \\
\text { avaliação precisa dos dados do sistema }\end{array}$ & 5 & 5 & 3 & 4 & 300 \\
\hline 3 & $\begin{array}{l}\text { Falta de autonomia na estratégia de manutenção do } \\
\text { sistema de refrigeração }\end{array}$ & 5 & 5 & 2 & 2 & 100 \\
\hline 4 & $\begin{array}{l}\text { Operação da manutenção sem procedimentos } \\
\text { formalizados (purgas, horário de operação, horário } \\
\text { de degelo e horário de desligamento) }\end{array}$ & 5 & 5 & 1 & 2 & 50 \\
\hline 5 & $\begin{array}{l}\text { Amônia é reutilizada em outras instalações e não } \\
\text { eram feitas análises do fluido periodicamente }\end{array}$ & 4 & 5 & 4 & 2 & 160 \\
\hline
\end{tabular}

Fonte: autores (2018).

\subsubsection{Plano de Ação e execução (5W2H)}

Com as causas fundamentas claras e definidas, foi elaborado o plano de ação conforme recursos pessoais e financeiros disponíveis. 


\section{Melhoria na eficiência energética de um armazém frigorificado através do método PDCA}

Grande parte das ações deste plano foram executadas em feriados, devido ao menor fluxo de pessoas no armazém e segurança, pois conforme dito anteriormente a amônia é um gás altamente tóxico. Este plano está detalhado no apêndice I - Plano de Ação: 5W2H.

\subsubsection{Verificação}

Para verificação das ações implementadas, utilizamos as ferramentas para medição do consumo energético (em kwh) e volume movimentado (em toneladas) no armazém: Webenergy e SAP respectivamente. Havia sido estipulada uma meta de redução de sete por cento deste indicador (kwh / ton) e através de gráficos elaborados no software Minitab obtivemos resultados satisfatórios e acima do esperado. O gráfico da figura 10 demonstra este indicador comparando o mesmo período (setembro a novembro) de dois mil e dezessete e dois mil e dezoito.

Figura 10 - Comparação de resultados

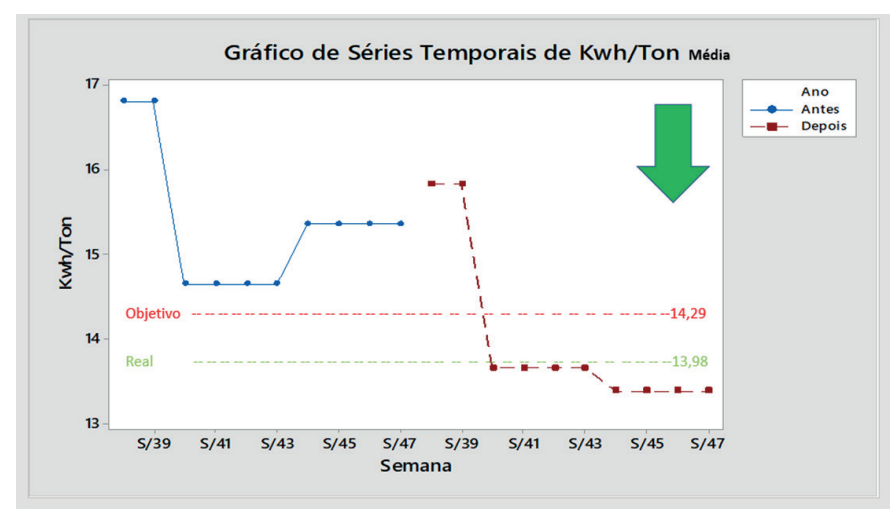

Fonte: autores (2018). 


\section{Melhoria na eficiência energética de um armazém frigorificado através do método PDCA}

O objetivo deste trabalho era melhorar a eficiência da operação deste armazém. Como consequência, o projeto apresentou ganhos financeiros que contribuíram ainda mais para seu sucesso. Estes ganhos estão demonstrados por período nos gráficos das figuras 11 e 12:

\section{Figura 11 - Redução de custo com energia elétrica}

\section{Representação dos ganhos}

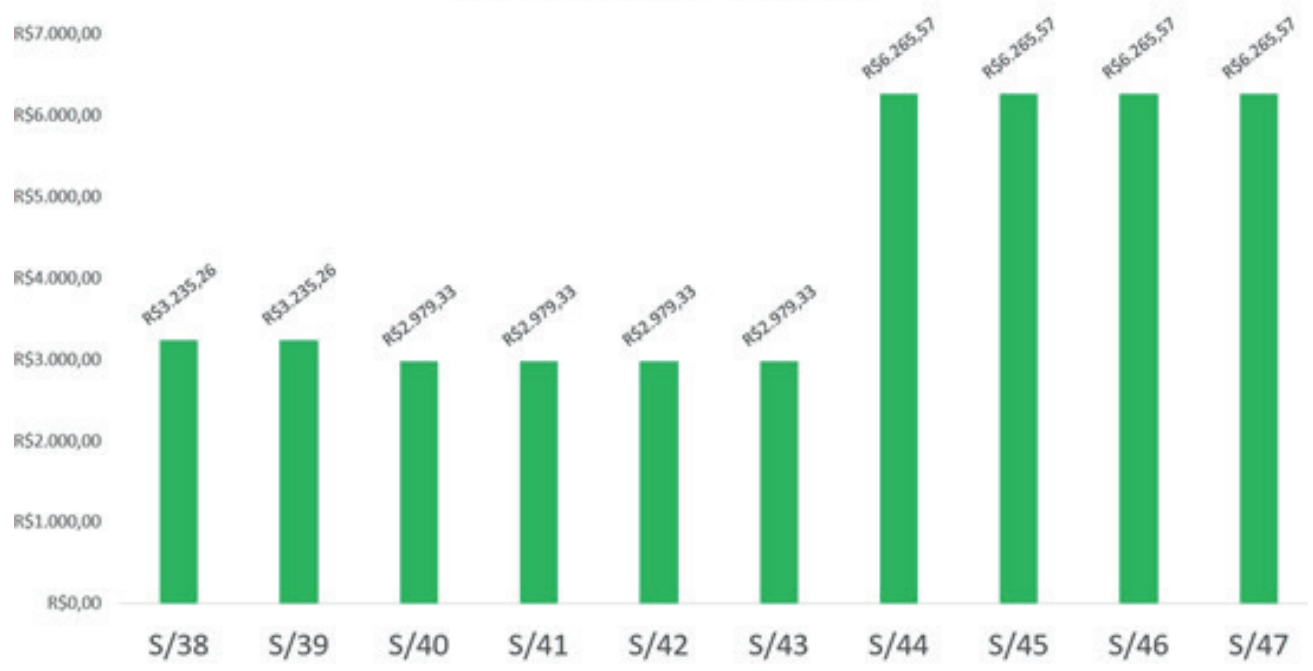

Fonte: autores (2018). 


\section{Melhoria na eficiência energética de um armazém frigorificado através do método PDCA}

Figura 12 - Redução de custo: Meta X Real

Representação dos ganhos

\begin{abstract}
$\mathrm{R} \$ 50.000,00$
$\mathrm{R} \$ 45.000,00$

$\mathrm{R} \$ 40.000,00$

$\mathrm{R} \$ 35.000,00$

$\mathrm{R} \$ 30.000,00$

$\mathrm{R} \$ 25.000,00$

$\mathrm{R} \$ 20.000,00$

$\mathrm{R} \$ 15.000,00$

$\mathrm{R} \$ 10.000,00$

$\mathrm{R} \$ 5.000,00$

$\mathrm{R} \$-$
\end{abstract}

$R \$ 30.113,99$

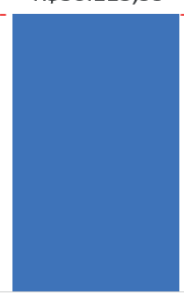

Meta

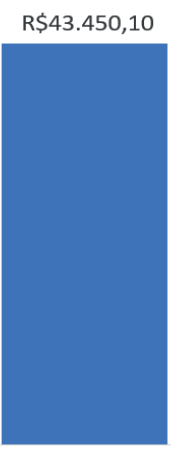

Real

Fonte: autores (2018).

\subsubsection{Padronização}

Para manter o bom resultado atingido, precisamos padronizar o processo. Além das ações citadas no $5 \mathrm{~W} 2 \mathrm{H}$ foram implantados os planos de manutenção preditiva e preventiva dos equipamentos, rotinas de inspeção e lubrificação, treinamento formal a toda equipe e publicação de procedimentos relacionados ao sistema de refrigeração na intranet da empresa. 


\section{Melhoria na eficiência energética de um armazém frigorificado através do método PDCA}

\section{Conclusões}

O objetivo deste trabalho foi melhorar a performance e eficiência energética de um armazém frigorífico. Através da utilização do método PDCA pudemos aprofundar o conhecimento no sistema de refrigeração e nesta poderosa ferramenta de gestão. Vimos que dominando esta ferramenta podemos resolver problemas e melhorar resultados.

Tivemos muitas dificuldades no decorrer do projeto, como o tempo hábil para entrega do projeto, a indisponibilidade para reuniões dos alunos envolvidos (horários incompatíveis, compromissos pessoais) e complexidade do tema abordado. Por se tratar de um sistema desconhecido e estrutura precária, nos deparamos com situações graves como soldas mal executadas, cabos fora de leito e manutenção precária.

As ações foram executadas em sua maioria nos feriados devido a menor quantidade de pessoas próximas e o risco tóxico já mencionado do fluido refrigerante (amônia anidra). Ao verificar o resultado, tivemos uma grande satisfação pelo atingimento do nosso objetivo e sensação de dever cumprido. Desenvolvemos pessoas, aprendemos com o método PDCA, ampliamos nosso conhecimento e obtivemos um excelente resultado.

Vale ressaltar que as manutenções realizadas foram emergenciais e ainda há muito o que ser feito em dois mil e dezenove. Porém com as atividades e ações mapeadas neste projeto, seremos mais assertivos nos prazos e ações.

As próximas etapas incluem a troca de trechos de tubulação, troca de válvulas danificadas, reparos na estrutura civil da sala de máquinas e investimentos em sistemas supervisórios, automação e controle, além de investimentos em detecção de amônia (melhoria em segurança). O PDCA é melhoria contínua, e o próximo passo e rodar novamente o ciclo afim de identificar novas oportunidades de melhoria e desperdício de recursos. 


\section{Melhoria na eficiência energética de um armazém frigorificado através do método PDCA}

\section{Referências}

BONIFÁCIO, T. C. C. Método de análise e solução de problemas (MASP): formação de white belts. 2.ed. Volkswagen do Brasil, 2006.

CAMPOS, V. F. Controle da Qualidade Total: no Estilo Japonês. 2. ed. Belo Horizonte: Fundação Christiano Ottoni, 1992.

GIL, A. C. Como Elaborar Projetos de Pesquisa. 5a ed. São Paulo. Atlas, 2010.

ISHIKAWA, K. TQC - Total Quality Control: estratégia e administração da qualidade que asseguram a prosperidade da empresa. São Paulo, IMC-Internacional Sistemas Educativos, 1986.

KANAANE, R.; ORTIGOSO, S. A. F. Manual de treinamento e desenvolvimento do potencial humano. São Paulo: Atlas, 2001.

OTAMI, N.; FIALHO, F. A. P. TCC: Métodos e Técnicas. $2^{\mathrm{a}}$ ed. Florianópolis. Visual Books, 2011.

PALADINI, E. P. Gestão da qualidade: teoria e prática. São Paulo: Atlas, 2008.

PONTES, B. R. Avaliação de desempenho: nova abordagem. 9. ed. São Paulo: 2005.

REYES, A. Implantação de um sistema de qualidade. São Paulo: USP, 2000. Disponível em: <http://www.esalq.usp.br/qualidade/pagexp1.htm>. Acesso em: 10 de novembro de 2019. 


\section{Melhoria na eficiência energética de um armazém frigorificado através do método PDCA}

SLACK, N. CHAMBERS, S.; JOHNSTON, R. Administração da produção. São Paulo: Atlas, 2002.

STOECKER, W. F.; JABARDO, J. M. S. Refrigeração Industrial. Edgard Blucher Ltda. 2. Ed. São Paulo, 2002.

WEBENERGY, 2018, disponível em: < http://www.webenergy.com.br/STM/Free/inicio.htm>. Acesso em: 10 de agosto de 2018.

WERKEMA, M. C. C. Métodos PDCA e Demaic e suas ferramentas analíticas. Rio de Janeiro: GEN Atlas. 2012.

Submetido em 13 de julho de 2020

Aceito em 20 de setembro de 2020

Publicado em 18 de dezembro de 2020 